\title{
Clinical Significance and Prevalence of Serum IGG4 Elevation in General Neurology
}

\author{
Hiroyuki Todo*, Ryuki Ando, Katsuya Nishida, Naonobu Futamura and Itaru Funakawa \\ Department of Neurology, National Hospital Organization Hyogo Chuo National Hospital, Japan
}

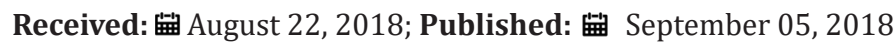

*Corresponding author: Hiroyuki Todo, Department of Neurology, National Hospital Organization Hyogo-Chuo National Hospital, Japan

Keywords: IgG4; Neuropathy; Prevalence

Abbreviations: AD: Alzheimer's Disease; ANCA: Antineutrophil Cytoplasmic Antibody; AP: Autoimmune Pancreatitis; BN: Beriberi Neuropathy; F: Female; IgG4-D: IgG4 Related Diseases; IMN: Immune Mediated Neuropathy; IgG: Immunoglobulin G; PACNS: Primary Angiitis of Central Nervous System; M: Male; PsyD: Psychogenic Disorders

\section{Introduction}

IgG4, a subclass of immunoglobulin G (IgG), can associate various neurological pathologies in three patterns; (i) pathogenicity of specific autoantibodies in IgG4 subclass (e.g. anti-neurofascin IgG4 antibodies), (ii) neurological manifestation (e.g. hypertrophic pachymeningitis) of IgG4-related diseases (IgG4-RD) and (iii) participation of IgG4 with other clinical entity (e.g. antineutrophil cytoplasmic antibody (ANCA)-associated vasculitis) [1-5]. However, accurate prevalence and characteristics of neurological abnormality associated with IgG4 are not completely disclosed, especially in daily practice of clinical neurology. Thereby, we authors were motivated to examine serum IgG4 level as the simple and efficient way because it often elevates in IgG4 RD (especially>135 mg/dL as a commonly used cutoff) and other inflammatory/dysimmune disorders, i.e. pattern (ii) and (iii) above $[3,6,7]$. On the contrary, it was difficult to examine specific autoantibodies in IgG4 subclass in pattern (i) above in our situation.

\section{Results}

Table 1: Clinical profiles of the patients with elevated level of serum IgG4.

\begin{tabular}{|c|c|c|c|c|c|c|c|}
\hline Case & Age (year-old) & Sexuality & Diagnosis & $\begin{array}{c}\text { Serum IgG4 } \\
\text { (mg/dL) }\end{array}$ & $\begin{array}{c}\text { IgG4/IgG ratio } \\
\text { (\%) }\end{array}$ & $\begin{array}{c}\text { Other Organ } \\
\text { Involvement }\end{array}$ & \begin{tabular}{c} 
Autoantibody \\
\hline 1
\end{tabular} \\
\hline 64 & F & IMN & 178 & 16.6 & Absent & Negative \\
\hline 2 & 49 & M & IMN & 118 & 8.6 & Absent & Negative \\
\hline 3 & 71 & M & PACNS & 259 & 10.4 & Absent & PR3-ANCA \\
\hline 4 & 80 & M & BN & 438 & 20.3 & AP & Negative \\
\hline 5 & 83 & M & AD & 131 & 7.6 & Absent & SS-A, SS-B \\
\hline 6 & 61 & F & PsyD & 236 & 16.2 & Absent & Negative \\
\hline 7 & 39 & M & PsyD & 189 & 15.4 & Absent & Negative \\
\hline
\end{tabular}


The age was $65.4 \pm 18.2$ year old, and male (M): female (F) number was 36:31 in enrolled 67 patients. 7 (10.4\%) of the patients showed IgG4 elevation ( $>117 \mathrm{mg} / \mathrm{dL})$, and in $5(7.5 \%)$ patients IgG4 level was $>135 \mathrm{mg} / \mathrm{dL}$, the commonly used cutoff line of IgG4RD (Figure 1A). Elevation of IgG4/IgG ratio > $8 \%$, the precedently used cutoff line, was observed in 6 of 7 patients with $\operatorname{IgG} 4>117$ $\mathrm{mg} / \mathrm{dL}$ while 1 of 60 patients with IgG4 $\leq 117 \mathrm{mg} / \mathrm{dL}$ (Figure 1B) and (Table 1) [7]. In total 67 patients, IgG4 level was $61.5 \pm 67.9 \mathrm{mg} /$ $\mathrm{dL}$, total IgG level was $1338.9 \pm 402.1 \mathrm{mg} / \mathrm{dL}$ and $\mathrm{IgG} 4 / \mathrm{IgG}$ ratio were $4.4 \pm 3.8 \%$. The number of diagnosis in the group with IgG4 elevation was; immune mediated neuropathy (IMN) $=2$, primary angiitis of central nervous system (PACNS) $=1$, beriberi neuropathy (BN) with nonsymptomatic autoimmune pancreatitis $(\mathrm{AP})=1$, Alzheimer's disease (AD) $=1$, and psychogenic disorders (PsyD) $=2$ (Table 1). Except case 4, none of the enrolled 67 patients had involvement of other organs within the spectrum of IgG4-RD (e.g. lymphadenopathy).

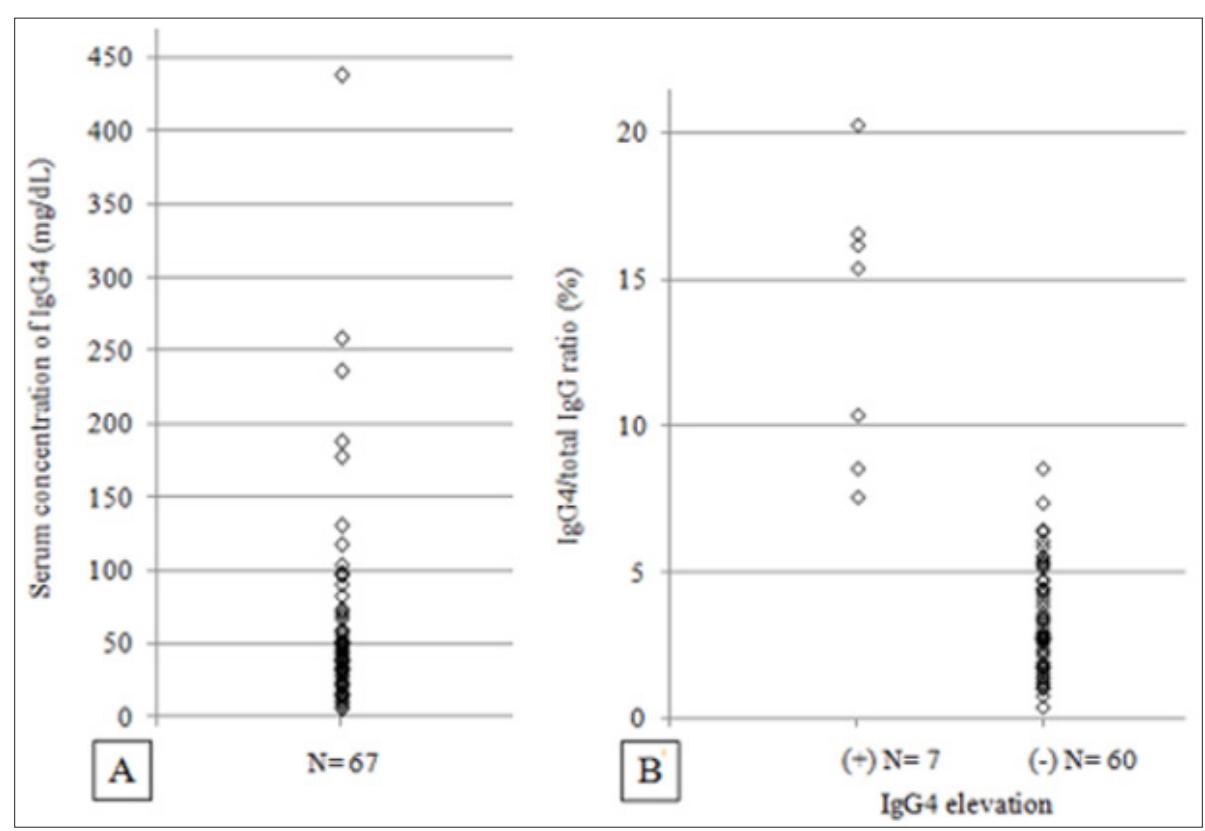

Figure 1: Distribution of serum IgG4 level (A) and IgG4/total IgG ratio (B).

Case 4 was diagnosed as $\mathrm{BN}$ because of low plasma thiamine level (13ng/mL, normal range: 29-66ng/mL) and subsequent amelioration of the neuropathy by thiamine replacement, while treatment by steroid showed no response. Coexistent positivity of autoantibodies with IgG4 elevation was observed in several, although not all, patients (case 3 and 5). These autoantibodies were considered as incidental in case 5 because this case did not have any inflammatory signs (e.g. fever). However, case 3 was clinically diagnosed as PACNS by recurrent brain infarction with persistent fever and inflammatory reaction of blood test. PsyD were diagnosed by history of precedent mental stress with the normal results of physical, radiological, and electrophysiological examination. Notably, case 1 and 2 with IMN shared common features of asymmetric, painful, sensory-dominant, and steroidresponsive neuropathy of extremities, while nerve conduction study (NCS) showed axonal injury with mild demyelination in case 1 and only mild demyelination in case 2 . In both cases, treatment by intravenous methylprednisolone and subsequent oral prednisolone lead to remission of dysesthesia with refractory hypoesthesia with normalization of posttreatment serum IgG4 level (105 and $114 \mathrm{mg} / \mathrm{dL}$ in case 1 and 2, respectively). Additional treatment by intravenous immunoglobulin (IVIg) in case 1 showed no further amelioration. Histopathological workups by biopsy or autopsy of any organs were not performed in any of the enrolled 67 patients.

\section{Discussion and Conclusion}

In this exploratory survey, we show the prevalence of serum IgG4 elevation with clinical course in 67 patients of general neurology. It seems rational that the prevalence $(7.5 \%)$ of serum IgG4 elevation $>135 \mathrm{mg} / \mathrm{dL}$ in our patients was lower than the previous report $(23.4 \%)$ of highly-selected patients who under underwent sural nerve biopsy in the specialized institution under the suspicion of inflammatory neuropathy [3]. Referring reports of various pancreatobiliary diseases with prevalence of IgG4 elevation in $0-36 \%$, the prevalence in our reports might be plausible [8]. We also examined clinical significance of IgG4 elevation, showing that IgG4 elevation can associate several autoantibodies (e.g. ANCA), while sole elevation of IgG4 can be observed, furthermore presence of IgG4 elevation did not necessarily mean specific pathologies. Thus, we concluded that clinical significance of serum IgG4 elevation itself was not confirmatory for the presence of specific neurologic disorders or other organ involvements in our survey. However, notifying common clinical phenotype of our case 1 and 2 , we speculated that vasculitic neuropathy with severe phenotype in case 1 lead to axonal degeneration, while mild phenotype in case 
2 lead to only demyelination, considering precedent reports of neuropathy in IgG4-RD $[5,9,10]$.

However, we could not exclude the possibility of incidental IgG4 elevation and participation of specific antibodies which were unable to be examined in our institutions, e.g. anti-Caspr antibody [11]. Lack of response for IVIg in case 1 could be a supporting evidence of IgG4 participation because IgG4 do not affect complement and Fc domain receptor as the hypothesized targets of IVIg [5]. Precedent reports had perspectives that neuropathy was a partial manifestation of systemic diseases, however, our case 1 and 2 can propose a new perspective that IgG4 can be a pathologic contributor for solely neuropathic form $[9,10,12,13]$. As a conclusion, the prevalence of serum IgG4 elevation in the screening of general neurology could be approximately $7-10 \%$ in the different cutoff lines (>117 or 135 $\mathrm{mg} / \mathrm{dL}$ ), and the elevation of serum IgG4 not necessarily meant specific neurological disorders. However, if the elevation of IgG4 was associated with IMN, it might be manifestation of a specific clinical entity. However, further investigations are required owing to limitations such as insufficient sample size, heterogeneity of the diseases and absence of histopathologic investigation, and disunity of diagnostic workup and treatment.

\section{References}

1. Koneczny I (2018) A New Classification System for IgG4 Autoantibodies. Front Immunol 9: 97

2. Abdel Razek MA, Venna N, Stone JH (2018) IgG4-related disease of the central and peripheral nervous systems. Lancet Neurol 17(2): 183-192.

3. Ohyama K, Koike H, Takahashi M, Kawagashira Y, Iijima M, et al. (2015) Immunoglobulin G4-related pathologic features in inflammatory neuropathies. Neurology 85(16): 1400-1407.

ISSN: 2574-1241

DOI: $10.26717 / B J S T R .2018 .08 .001695$

Hiroyuki Todo. Biomed J Sci \& Tech Res

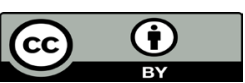

This work is licensed under Creative Commons Attribution 4.0 License

Submission Link: https://biomedres.us/submit-manuscript.php
4. Baptista B, Casian A, Gunawardena H, D Cruz D, Rice CM (2017) Neurological Manifestations of IgG4-Related Disease. Curr Treat Options Neurol 19(4): 14.

5. Querol L, Nogales Gadea G, Rojas Garcia R, Diaz Manera J, Pardo J, et al. (2014) Neurofascin IgG4 antibodies in CIDP associate with disabling tremor and poor response to IVIg. Neurology 82(10): 879-886.

6. Hao M, Liu M, Fan G, Yang X, Li J (2016) Diagnostic Value of Serum IgG4 for IgG4-Related Disease: A PRISMA-compliant Systematic Review and Meta-analysis. Medicine (Baltimore) 95(21): e3785.

7. Carruthers MN, Khosroshahi A, Augustin T, Deshpande V, Stone JH (2015) The diagnostic utility of serum IgG4 concentrations in IgG4related disease. Ann Rheum Dis 74(1): 14-18.

8. Hart PA, Smyrk TC, Chari ST (2015) Lymphoplasmacytic sclerosing pancreatitis without IgG4 tissue infiltration or serum IgG4 elevation: IgG4-related disease without IgG4. Mod Pathol 28(2): 238-247.

9. Ohyama K, Koike H, Iijima M, Hashimoto R, Tomita M, et al. (2013) IgG4related neuropathy: a case report, JAMA Neurol;70(4): 502-505.

10. Suzuki Y, Shiraishi M, Yamada K, Doi M, Kato M, et al. (2016) A case of refractory IgG4-related peripheral neuropathy with severe axonal damage. Rinsho Shinkeigaku 56(5): 323-327.

11. Doppler K, Appeltshauser L, Villmann C, Martin C, Peles E, et al. (2016) Auto-antibodies to contactin-associated protein 1 (Caspr) in two patients with painful inflammatory neuropathy. Brain 139(Pt 10): 26172630.

12. Yokoi S, Kawagashira Y, Ohyama K, Iijima M, Koike H, et al. (2014) Mononeuritis multiplex with tumefactive cellular infiltration in a patient with reactive lymphoid hyperplasia with increased immunoglobulin G4positive cells. Hum Pathol 45(2): 427-430.

13. Waheed Nickerson J, Ambaye AB, Babi MA, Tandan R (2015) IgG4Related Neuromyopathy Associated with Recurrent Pleural Effusion: J Clin Neuromuscul Dis 16(4): 210-219.

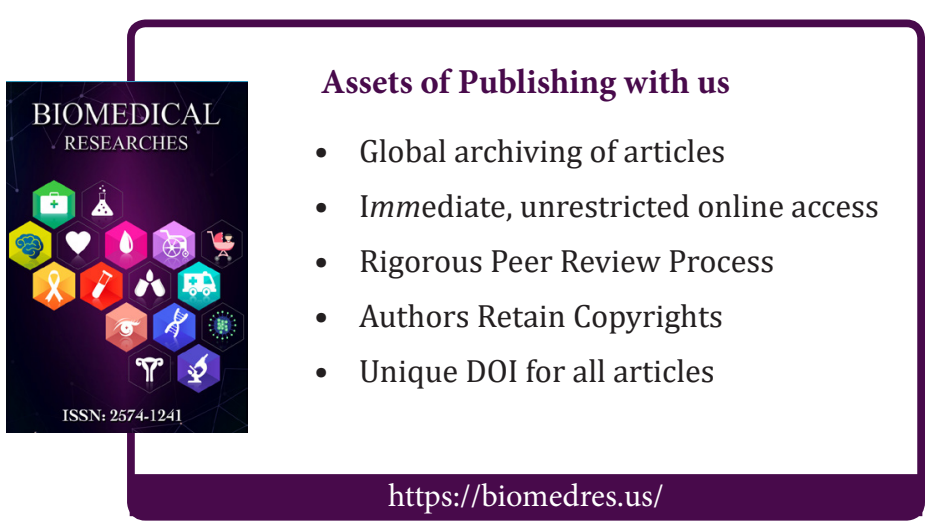

